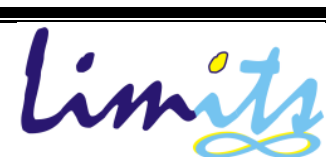

Limits: Journal of Mathematics and Its Applications

E-ISSN: 2579-8936

P-ISSN: $1829-605 \mathrm{X}$

Vol. 16, No. 2, Desember 2019, 105-116

DOI: http://dx.doi.org/10.12962/limits.v16i2.5872

\title{
Pemodelan Dan Optimasi Multi-Tujuan Portofolio Saham Dengan Resiko Menggunakan Nadir Compromise Programming
}

\author{
Subchan, E. Rahmawati \\ Departemen Matematika, Fakultas Sains dan Analitika Data \\ Institut Teknologi Sepuluh Nopember, Surabaya \\ e-mail: subchan@matematika.its.ac.id
}

Diajukan:2 September 2019 Diperbaiki: 14 Nopember 2019 Diterima:12 Desember 2019

\begin{abstract}
Abstrak
Portofolio saham merupakan kumpulan aset yang dimiliki oleh perusahaan maupun perseorangan. Pada paper ini dibahas pemodelan dan optimasi portofolio saham dengan memperhatikan beberapa criteria, yaitu optimasi risiko, maksimum expected return dan minimum modal investasi. Pemodelan permasalahan menghasilkan optimasi multi-tujuan yang selanjutnya diselesaikan dengan menggunakan metode Nadir Compromise Programming. Pada penelitian dianalisis 20 saham dari 5 sektor. Dari hasil optimasi dihasilkan 11 saham terpilih dengan nilai expected return maksimal dan modal investasi sebesar 7820,66. Berdasar Indeks Harga Saham Gabungan (IHSG) diperoleh expected return portofolio yang nilainya lebih besar daripada expected return pasar.
\end{abstract}

Kata kunci: Pemodelan portofolio saham, nadir compromise programming, optimasi multi-tujuan.

\begin{abstract}
Stock portfolio is a collection of assets from companies or individuals. In order to achieve the purpose of portfolio investment, it is required to optimize the problem. This paper discusses modelling and optimization of portfolio by considering several criteria, which are the risk, expected return and capital investment. In this paper a multi-objective portfolio optimization problem is modelled and then solved using the Nadir Compromise Programming method for 20 stocks in 5 sectors. Based on the simulation result, 11 stocks are selected with a maximum value of expected return and the capital investment is 7820.66. Based on Jakarta Stock Exchange, the expected return value of portfolio is greater than the expected return on the market.
\end{abstract}

Keywords: Stock portfolio modeling, nadir compromise programming, multi-objective optimization.

\section{Pendahuluan}

Saham adalah aset finansial yang paling menguntungkan dan menjadi unggulan di kalangan investor. Saham merupakan salah satu aset finansial yang diperdagangkan di pasar modal. Investasi pada sektor ini menawarkan tingkat keuntungan yang tinggi dibandingkan dengan investasi di sektor aset real, seperti pembelian aset produktif, pendirian pabrik, pembukaan 
pertambangan dan lainnya. Namun dalam berinvestasi semakin tinggi tingkat return yang ditawarkan maka semakin tinggi pula tingkat resiko yang dihadapi. Investor pada umumnya menginginkan return yang maksimal dengan resiko yang minimal, sehingga sebelum menanamkan modalnya investor harus melakukan analisis agar tujuan dalam berinvestasi tercapai. Salah satu cara untuk meminimalkan resiko yaitu dengan melakukan diversifikasi atau penyebaran investasi dengan membentuk portofolio yang terdiri dari beberapa saham.

Portofolio merupakan kombinasi atau gabungan dari sekumpulan aset, baik berupa aset finansial maupun aset real yang dimiliki oleh investor [1, 2]. Portofolio disusun untuk mendapatkan keuntungan yang maksimal, sehingga dalam permasalahan optimasi portofolio terdapat beberapa fungsi tujuan yang dipertimbangkan investor, yaitu memaksimalkan tingkat pengembalian yang diharapkan dan meminimalkan resiko [3].

Teori portofolio modern dicetuskan oleh Markowitz [7], dimana Markowitz menggunakan pemilihan portofolio sebagai model optimasi yang dikenal dengan model mean-variance dengan melibatkan dua fungsi tujuan yaitu memaksimalkan expected return dan meminimumkan resiko $[5,6,8]$. Dalam permasalahan pemilihan portofolio dianalisa bagaimana mengalokasikan modal agar memperoleh keuntungan maksimal dengan resiko yang minimal [5, 6, 8]. Ciptaningrum [3] membahas tentang pemilihan portofolio dengan masalah optimasi dengan dua fungsi tujuan yaitu memaksimalkan expected return dan meminimalkan resiko dengan menggunakan metode Compromise Programming sehingga didapatkan lima portofolio yang efisien.

Pada paper ini digunakan Nadir Compromise Programming (NCP) dalam menyelesaikan permasalahan multi-tujuan pada model optimasi portofolio. Nadir Compromise Programming adalah pengembangan dari metode Compromise Programming yang dapat digunakan untuk mengoptimalkan permasalahan multi-tujuan, sehingga dapat menentukan portofolio yang optimal dari sekumpulan saham.

\section{Metode Penelitian}

Penelitian diawali dengan pengumpulan data dan informasi. Data yang digunakan adalah data sekunder Indeks Harga Saham Gabungan (IHSG) selama 4 tahun yang diperoleh dari http://finance.yahoo.com/. Data yang digunakan meliputi opening price, closing price dari 20 perusahaan. Perusahaan-perusahaan tersebut dibedakan menjadi lima sektor, yaitu sektor energi dan metal, finansial, jasa, manufaktur dan perkebunan (lihat Tabel 1). 


\section{Menghitung Return, Expected Return dan Koefisien Resiko}

Dari hasil perhitungan return, dapat diketahui suatu saham untung atau rugi pada periode tertentu. Setelah diketahui return saham pada masing-masing periode maka dapat dihitung expected returnnya. Koefisien resiko dihitung dengan membandingkan return history asset dengan return pasar menggunakan kovarian masing-masing saham.

\section{Pemodelan dan Optimasi Portofolio}

Pada tahap ini dirancang model optimasi portofolio. Dalam pembentukan portofolio, investor selalu menginginkan return yang maksimal dengan resiko dan modal yang minimal. Oleh karena itu fungsi tujuan dari model optimasi portofolio terdiri dari 3 aspek, yaitu resiko, expected return dan modal investasi. Sedangkan fungsi kendala untuk model optimasi portofolio adalah koefisien resiko, jumlah proporsi dana yang diinvestasikan, serta batas atas dan batas bawah dana yang diinvestasikan.

Untuk menyelesaikan permasalahan tersebut digunakan Nadir Compromise Programming. Pada tahap ini didapatkan jumlah proporsi dana yang diinvestasikan pada masing-masing saham.

\section{Analisa dan Pembahasan}

Pada bagian ini dibahas tentang analisa dan pembahasan dari metoda yang digunakan.

\section{Perhitungan Return dan Expected Return Saham Individual}

Hasil dari investasi diukur dari pengembalian (return) yang diperoleh dalam periode waktu tertentu, Pengembalian sama dengan perubahan nilai saham dalam kurun waktu tertentu dibagi dengan nilai harga buka saham. Pengembalian saham individual dapat dihitung berdasarkan data historis harga saham yang dapat dihitung dengan:

$$
R_{i j}=\frac{C P-O P+\text { Dividen }}{O P}
$$

Berdasar pada nilai harga buka (Open Price, OP) dan harga tutup (Close Price, $\mathrm{CP}$ ) selama 4 tahun diperoleh nilai expected return $\boldsymbol{E}\left(\boldsymbol{R}_{\boldsymbol{i}}\right)$ masing-masing saham dengan menggunakan persamaan:

$$
E\left(R_{i}\right)=\sum_{j=1}^{N} \frac{E\left(R_{j}\right)}{N}
$$

Hasil dari perhitungan expected return dapat dilihat pada Tabel 1 kolom 3. 


\section{Perhitungan Koefisien Resiko}

Sebelum menghitung koefisien resiko masing-masing saham, terlebih dahulu dihitung return pasar atau tingkat pengembalian pasar. Return pasar $\left(R_{m}\right)$ yang diwakili oleh Indeks Harga Saham Gabungan (IHSG) dihitung dengan menggunakan persamaan:

$$
R_{m}=\frac{I H S G_{t}-I H S G_{t-1}}{I H S G_{t-1}}
$$

Koefisien resiko didapatkan dengan membandingkan kovarian saham-return pasar dengan varian return pasar. Sebelum menghitung nilai varian return pasar, terlebih dulu dihitung expected return pasar $\left(E\left(R_{m}\right)\right)$ dengan menggunakan persamaan:

$$
E\left(R_{m}\right)=\sum_{m=1}^{N} \frac{R_{m}}{N}
$$

Penelitian diawali dengan pengumpulan data dan informasi. Data yang digunakan adalah data sekunder Indeks Harga Saham Gabungan (IHSG) selama 4 tahun yang diperoleh dari http://finance.yahoo.com/. Data yang digunakan meliputi opening price, closing price dari 20 perusahaan. Perusahaan-perusahaan tersebut dibedakan menjadi lima sektor, yaitu sektor energi dan metal, finansial, jasa, manufaktur dan perkebunan (lihat Tabel 1).

\section{Menghitung Return, Expected Return dan Koefisien Risiko}

Dari hasil perhitungan return, dapat diketahui suatu saham untung atau rugi pada periode tertentu. Setelah diketahui return saham pada masing-masing periode maka dapat dihitung expected returnnya. Koefisien risiko dihitung dengan membandingkan return history asset dengan return pasar menggunakan kovarian masing-masing saham.

\section{Pemodelan dan Optimasi Portofolio}

Pada tahap ini dirancang model optimasi portofolio. Dalam pembentukan portofolio, investor selalu menginginkan return yang maksimal dengan risiko dan modal yang minimal. Oleh karena itu fungsi tujuan dari model optimasi portofolio terdiri dari 3 aspek, yaitu risiko, expected return dan modal investasi. Sedangkan fungsi kendala untuk model optimasi portofolio adalah koefisien risiko, jumlah proporsi dana yang diinvestasikan, serta batas atas dan batas bawah dana yang diinvestasikan. Untuk menyelesaikan permasalahan tersebut digunakan Nadir Compromise Programming. Pada tahap ini didapatkan jumlah proporsi dana yang diinvestasikan pada masingmasing saham. 


\section{Analisa dan Pembahasan}

Hasil dari investasi diukur dari pengembalian (return) yang diperoleh dalam periode waktu tertentu, Pengembalian sama dengan perubahan nilai saham dalam kurun waktu tertentu dibagi dengan nilai harga buka saham. Pengembalian saham individual dapat dihitung berdasarkan data historis harga saham yang dapat dihitung dengan:

$$
R_{i j}=\frac{C P-O P+\text { Dividen }}{O P}
$$

Berdasar pada nilai harga buka (OP) dan harga tutup (CP) selama 4 tahun diperoleh nilai expected return $\boldsymbol{E}\left(\boldsymbol{R}_{\boldsymbol{i}}\right)$ masing-masing saham dengan menggunakan persamaan:

$$
E\left(R_{i}\right)=\sum_{j=1}^{N} \frac{E\left(R_{j}\right)}{N}
$$

Hasil dari perhitungan expected return dapat dilihat pada Tabel 1 kolom 3.

\section{Perhitungan Koefisien Risiko}

Sebelum menghitung koefisien risiko masing-masing saham, terlebih dahulu dihitung return pasar atau tingkat pengembalian pasar. Return pasar $\left(R_{m}\right)$ yang diwakili oleh Indeks Harga Saham Gabungan (IHSG) dihitung dengan menggunakan persamaan:

$$
R_{m}=\frac{I H S G_{t}-I H S G_{t-1}}{I H S G_{t-1}}
$$

\begin{tabular}{|c|c|c|c|c|c|c|}
\hline$i$ & Saham & $E\left(R_{i}\right)$ & $\operatorname{Cov}\left(R_{i}, R_{m}\right)$ & $\beta_{i}$ & $P_{i}$ & $\begin{array}{c}\text { Proporsi } \\
\text { dana }\end{array}$ \\
\hline 1 & ANTM (PT. Aneka Tambang) & 0,011317 & 0,004598 & 1,425593 & 1370 & 0,1 \\
\hline 2 & ITMG (PT. Indo Tambangraya Megah) & 0,031779 & 0,005218 & 1,617650 & 35500 & 0 \\
\hline 3 & PGAS (Perusahaan Gas Negara) & 0,030578 & 0,002560 & 0,793521 & 5950 & 0,1 \\
\hline 4 & INCO (Vale Indonesia Tbk ) & 0,012931 & 0,005126 & 1,589113 & 2375 & 0 \\
\hline 5 & PTBA (Tambang Batubara Bukit Asam) & 0,019030 & 0,004243 & 1,315604 & 14400 & 0 \\
\hline 6 & BBRI (Bank Rakyat Indonesia) & 0,033006 & 0,004633 & 1,436440 & 8750 & 0 \\
\hline 7 & BBNI (Bank Negara Indonesia) & 0,044089 & 0,005020 & 1,556309 & 5050 & 0,1 \\
\hline 8 & BMRI (Bank Mandiri Tbk) & 0,040642 & 0,005041 & 1,562884 & 10000 & 0 \\
\hline 9 & BBCA (Bank Central Asia Tbk) & 0,021789 & 0,002964 & 0,910525 & 11400 & 0,1 \\
\hline 10 & UNTR (United Tractors Tbk) & 0,039044 & 0,004363 & 1,352611 & 18200 & 0 \\
\hline 11 & TLKM (Telekomunikasi Indonesia) & 0,014841 & 0,001866 & 0,578510 & 11000 & 0,1 \\
\hline 12 & HEXA (Hexindo Adiperkasa Tbk) & 0,047049 & 0,003673 & 1,138862 & 5600 & 0,1 \\
\hline 13 & AKRA (AKR Corporindo Tbk) & 0,052403 & 0,003850 & 1,193499 & 5000 & 0 \\
\hline 14 & INDF (Indofood Sukses Makmur Tbk) & 0,0486686 & 0,004472 & 1,386301 & 7450 & 0,043214 \\
\hline 15 & KLBF (Kalbe Farma Tbk) & 0,070469 & 0,003363 & 1,042594 & 1240 & 0,1 \\
\hline 16 & MYOR (Mayora Indah Tbk) & 0,067446 & 0,004359 & 1,351373 & 27100 & 0 \\
\hline 17 & UNVR (Unilever Indonesia Tbk) & 0,025267 & 0,000937 & 0,290526 & 22800 & 0,056786 \\
\hline 18 & ASII (Astra International Tbk) & 0,063638 & 0,004581 & 1,420340 & 7900 & 0 \\
\hline 19 & LSIP (PP London Sumatra Indonesia Tbk) & 0,0357573 & 0,003735 & 1,157929 & 1930 & 0,1 \\
\hline 20 & AALI (Astra Agro Lestari Tbk) & 0,020352 & 0,002039 & 0,632100 & 18500 & 0,1 \\
\hline
\end{tabular}

Tabel 1. Data-data hasil perhitungan 
Koefisien risiko didapatkan dengan membandingkan kovarian saham-return pasar dengan varian return pasar. Sebelum menghitung nilai varian return pasar, terlebih dulu dihitung expected return pasar $\left(E\left(R_{m}\right)\right)$ dengan menggunakan persamaan:

$$
E\left(R_{m}\right)=\sum_{m=1}^{N} \frac{R_{m}}{N}
$$

Selanjutnya menghitung varian pasar $\left(\sigma_{m}^{2}\right)$ dengan menggunakan data return market yang diperoleh dari hasil perhitungan pada Persamaan (3). Setelah menghitung return market dan expected return market, selanjutnya dapat dihitung varians pasar dengan menggunakan persamaan:

$$
\sigma_{m}^{2}=\frac{\sum_{j=1}^{n}\left(R_{m j}-E\left(R_{m}\right)\right)^{2}}{N}
$$

Sedangkan perhitungan kovarian return saham dan return pasar dapat dihitung dengan menggunakan persamaan:

$$
\operatorname{Cov}\left(R_{i}, R_{m}\right)=\sum_{i=m=1}^{n} \sum_{j=1}^{N} \frac{\left(R_{i j}-E\left(R_{i}\right)\right)\left(R_{m j}-E\left(R_{m}\right)\right)}{N} .
$$

Dengan menggunakan Persamaan (6), didapatkan nilai kovarian return saham dengan return pasar masing-masing saham yang disajikan pada Tabel 1 kolom 4. Selanjutnya dapat dihitung koefisien resiko $(\beta)$ masing-masing saham. Tabel 1 kolom 5 merupakan hasil nilai koefisien resiko masing-masing saham yang didapatkan dengan menggunakan persamaan:

$$
\beta_{i}=\frac{\operatorname{Cov}\left(R_{i}, R_{m}\right)}{\sigma_{m}^{2}} .
$$

\section{Model Optimasi Portofolio}

Tujuan pembentukan portofolio adalah untuk mengurangi resiko dengan cara diversifikasi, yaitu mengalokasikan sejumlah dana pada berbagai alternatif investasi. Pemodelan optimasi portofolio memperhatikan tiga aspek yaitu resiko, expected return dan modal investasi. Sedangkan variabel keputusannya adalah mendapatkan proporsi dana yang akan diinvestasikan pada masingmasing saham dalam portofolio tersebut. Model optimasi portofolio saham didefinisikan sebagai berikut,

\section{Fungsi tujuan}

Optimum resiko

$$
\text { Opt } f_{1}=\sum_{i=1}^{20} \beta_{i} x_{i}
$$

Maksimum expected return

$$
\operatorname{Max} f_{2}=\sum_{i=1}^{20} E\left(R_{i}\right) x_{i}
$$


Minimum modal investasi

$$
\min f_{3}=\sum_{i=1}^{20} P_{i} x_{i}
$$

$x_{i}:$ proporsi dana yang diinvestasikan pada saham ke $\mathrm{i}$

\section{Fungsi kendala}

Kendala jumlah dana yang diinvestasikan dimodelkan sebagai berikut,

$$
\sum_{i=1}^{20} x_{i}=1
$$

Perumusan fungsi kendala jumlah dana pada lima sektor, yaitu 20 persen pada sektor energi dan metal (untuk saham $i=1,2,3,4,5$ ), 20 persen pada sektor finansial (untuk saham $i=6,7,8,9$ ), 20 persen pada sektor jasa (untuk saham $i=10,11,12,13$ ), 20 persen pada sektor manufaktur (untuk saham $i=14,15,16,17,18$ ) dan 20 persen untuk saham $i=19,20$ ). Fungsi kendala dapat dituliskan sebagai berikut,

$$
\begin{aligned}
& x_{1}+x_{2}+x_{3}+x_{4}+x_{5}=0,2, \\
& x_{6}+x_{7}+x_{8}+x_{9}=0,2, \\
& x_{10}+x_{11}+x_{12}+x_{13}=0,2, \\
& x_{14}+x_{15}+x_{16}+x_{17}+x_{18}=0,2, \\
& x_{19}+x_{20}=0,2 .
\end{aligned}
$$

Batas bawah dan batas atas dana yang diinvestasikan,

$$
0 \leq x_{i} \leq 0,1 \text {, untuk } i=1,2,3 \ldots, 20 .
$$

\section{Nadir Compromise Programming}

Sebelum merumuskan kedalam Nadir Compromise Programming, maka terlebih dahulu dicari nilai Nadir dari fungsi tujuan maksimum dan minimum, dengan cara mengoptimasi masingmasing fungsi tujuan dengan fungsi kendala yang ada.

\section{Nilai ideal dan Nadir expected return portofolio}

Untuk portofolio yang terdiri dari 20 saham, nilai ideal expected return dapat dituliskan sebagai berikut,

$$
\begin{aligned}
& \operatorname{Max} 0,011317 x_{1}+0,031779 x_{2}+0,030578 x_{3}+0,012931 x_{4}+0,019030 x_{5}+ \\
& 0,033006 x_{6}+0,044089 x_{7}+0,040642 x_{8}+0,021789 x_{9}+0,039044 x_{10}+0,014841 x_{11}+ \\
& 0,047049 x_{12}+0,052403 x_{13}+0,0486686 x_{14}+0,070469 x_{15}+0,067446 x_{16}+0,025267 x_{17}+ \\
& 0,063638 x_{18}+0,0357573 x_{19}+0,020352 x_{20},
\end{aligned}
$$


dengan kendala,

$x_{1}+x_{2}+x_{3}+x_{4}+x_{5}=0,2$,

$x_{6}+x_{7}+x_{8}+x_{9}=0,2$,

$x_{10}+x_{11}+x_{12}+x_{13}=0,2$,

$x_{14}+x_{15}+x_{16}+x_{17}+x_{18}=0,2$,

$x_{19}+x_{20}=0,2$,

$0 \leq x_{i} \leq 0,1 \quad i=1,2,3 \ldots, 20$.

Nilai ideal expected return $f_{2}$ pada 20 saham adalah $f_{2}=0,04405643$. Dalam permasalahan multi-tujuan, nilai Nadir adalah nilai yang berlawanan dengan nilai ideal dan didapatkan dari nilai solusi yang terburuk. Sehingga perhitungan untuk nilai Nadir maksimal expected return sebagai berikut,

$$
\begin{aligned}
& \text { Min 0,011317 } x_{1}+0,031779 x_{2}+0,030578 x_{3}+0,012931 x_{4}+0,019030 x_{5}+ \\
& 0,033006 x_{6}+0,044089 x_{7}+0,040642 x_{8}+0,021789 x_{9}+0,039044 x_{10}+ \\
& 0,014841 x_{11}+0,047049 x_{12}+0,052403 x_{13}+0,0486686 x_{14}+0,070469 x_{15}+ \\
& 0,067446 x_{16}+0,025267 x_{17}+0,063638 x_{18}+0,0357573 x_{19}+0,020352 x_{20}
\end{aligned}
$$

dengan kendala yang sama. Nilai Nadir expected return $f_{2^{*}}$ adalah 0,02629729 .

\section{Nilai ideal dan Nadir modal investasi}

Nilai ideal modal investasi dapat dituliskan sebagai berikut,

$$
\begin{aligned}
& \min 1370 x_{1}+35500 x_{2}+5950 x_{3}+2375 x_{4}+14400 x_{5}+8750 x_{6}+5050 x_{7}+10000 x_{8}+ \\
& 11400 x_{9}+18200 x_{10}+11000 x_{11}+5600 x_{12}+5000 x_{13}+7450 x_{14}+1240 x_{15}+ \\
& 27100 x_{16}+22800 x_{17}+7900 x_{18}+1930 x_{19}+18500 x_{20}
\end{aligned}
$$

dengan kendala yang sama. Dari hasil perhitungan diperoleh nilai ideal minimasi modal investasi adalah $f_{3}=5726,5$. Sedangkan closing price dari 20 saham disajikan pada Tabel 1 kolom 5 .

Perhitungan untuk nilai Nadir minimasi dana dapat dituliskan sebagai berikut,

$$
\begin{aligned}
\max & 1370 x_{1}+35500 x_{2}+5950 x_{3}+2375 x_{4}+14400 x_{5}+8750 x_{6}+5050 x_{7}+10000 x_{8}+ \\
& 11400 x_{9}+18200 x_{10}+11000 x_{11}+5600 x_{12}+5000 x_{13}+7450 x_{14}+1240 x_{15}+ \\
& 27100 x_{16}+22800 x_{17}+7900 x_{18}+1930 x_{19}+18500 x_{20}
\end{aligned}
$$

dengan kendala yang sama. Nilai Nadir minimasi modal investasi adalah $f_{3^{*}}=17083$. 


\section{Fungsi Tujuan Nadir Compromise Programming}

Untuk memperoleh penyelesaian kompromi dari ketiga fungsi tujuan digunakan Nadir Compromise Programming. Perhitungan fungsi tujuan Nadir Compromise Programming ini dilakukan dengan asumsi semua fungsi tujuan mempunyai bobot $w$ sama dan total nilai total bobot $p$ adalah satu, sehingga nilai $w_{1}=1 / 3$ (resiko), $w_{2}=1 / 3$ (expected return) dan $w_{3}=1 / 3$ (modal investasi) maka fungsi tujuan Nadir Compromise Programming dapat diformulasikan sebagai berikut,

$$
\operatorname{Min}\left[w_{1}\left(\delta_{1}^{+}+\delta_{1}^{-}\right)+w_{2}\left(-\delta_{2}^{+}\right)+w_{3}\left(-\delta_{3}^{-}\right)\right]
$$

dengan kendala:

$f_{1}-\delta_{1}^{+}=1$

$f_{1}+\delta_{1}^{-}=1$

$f_{2}-\delta_{2}^{+}=f_{2^{*}}$,

$f_{3}+\delta_{3}^{-}=f_{3^{*}}$,

$x_{1}+x_{2}+x_{3}+x_{4}+x_{5}=0,2$,

$x_{6}+x_{7}+x_{8}+x_{9}=0,2$,

$x_{10}+x_{11}+x_{12}+x_{13}=0,2$,

$x_{14}+x_{15}+x_{16}+x_{17}+x_{18}=0,2$,

$x_{19}+x_{20}=0,2$,

$0 \leq x_{i} \leq 0,1 \quad i=1,2,3 \ldots, 20$,

$\delta_{1}^{+} \geq 0 ; \delta_{1}^{-} \geq 0 ; \delta_{2}^{+} \geq 0 ; \delta_{3}^{-} \geq 0$,

dengan,

$w_{k}$ : bobot preferensi tujuan ke- $k$,

$\delta_{k}^{+} \quad$ : variabel deviasi positif ke- $k$,

$\delta_{k}^{-} \quad$ : variabel deviasi negatif ke- $k$,

$f_{k} \quad$ : fungsi tujuan ke- $k$,

$f_{k^{*}} \quad$ : fungsi tujuan ke- $k$ berdasarkan nilai Nadir,

$x_{i} \quad$ : proporsi dana yang diinvestasikan pada saham $i$.

\section{Perhitungan Proporsi Dana}

Perhitungan proporsi dana untuk masing-masing saham dapat dirumuskan sebagai berikut,

$\operatorname{Min}\left[0.333 \times\left(\delta_{1}^{+}+\delta_{1}^{-}\right)+0.333 \times\left(-\delta_{2}^{+}\right)+0.333 \times\left(-\delta_{3}^{-}\right)\right]$ 
dengan kendala:

$$
\begin{aligned}
& 1,425593 x_{1}+1,617650 x_{2}+0,793521 x_{3}+1,589113 x_{4}+1,315604 x_{5}+1,436440 x_{6} \\
& +1,556309 x_{7}+1,562884 x_{8}+0,910525 x_{9}+1,352611 x_{10}+0,578510 x_{11} \\
& +1,138862 x_{12}+1,193499 x_{13}+1,386301 x_{14}+1,042594 x_{15}+1,351373 x_{16} \\
& +0,290526 x_{17}+1,420340 x_{18}+1,157929 x_{19}+0,632100 x_{20}-\delta_{1}^{+}=1 \\
& 1,425593 x_{1}+1,617650 x_{2}+0,793521 x_{3}+1,589113 x_{4}+1,315604 x_{5}+1,43644 x_{6} \\
& +1,556309 x_{7}+1,562884 x_{8}+0,910525 x_{9}+1,352611 x_{10}+0,578510 x_{11} \\
& +1,138862 x_{12}+1,193499 x_{13}+1,386301 x_{14}+1,042594 x_{15}+1,351373 x_{16} \\
& +0,290526 x_{17}+1,420340 x_{18}+1,157929 x_{19}+0,632100 x_{20}+\delta_{1}^{-}=1 \\
& 0,011317 x_{1}+0,031779 x_{2}+0,030578 x_{3}+0,012931 x_{4}+0,019030 x_{5}+0,033006 x_{6} \\
& +0,044089 x_{7}+0,040642 x_{8}+0,021789 x_{9}+0,039044 x_{10}+0,014841 x_{11} \\
& +0,047049 x_{12}+0,052403 x_{13}+0,0486686 x_{14}+0,070469 x_{15}+0,067446 x_{16} \\
& +0,025267 x_{17}+0,063638 x_{18}+0,0357573 x_{19}+0,020352 x_{20}-\delta_{2}^{+} \\
& =0,02629729 \\
& 1370 x_{1}+35500 x_{2}+5950 x_{3}+2375 x_{4}+14400 x_{5}+8750 x_{6}+5050 x_{7}+10000 x_{8}+11400 x_{9} \\
& +18200 x_{10}+11000 x_{11}+5600 x_{12}+5000 x_{13}+7450 x_{14}+1240 x_{15}+27100 x_{16}+ \\
& 22800 x_{17}+7900 x_{18}+1930 x_{19}+18500 x_{20}+\delta_{3}^{+}=17083 \\
& x_{1}+x_{2}+x_{3}+x_{4}+x_{5}=0,2 \text {, } \\
& x_{6}+x_{7}+x_{8}+x_{9}=0,2 \text {, } \\
& x_{10}+x_{11}+x_{12}+x_{13}=0,2 \text {, } \\
& x_{14}+x_{15}+x_{16}+x_{17}+x_{18}=0,2 \text {, } \\
& x_{19}+x_{20}=0,2 \text {, } \\
& 0 \leq x_{i} \leq 0,1 \quad i=1,2,3 \ldots, 20 \text {, } \\
& \delta_{1}^{+} \geq 0 ; \delta_{1}^{-} \geq 0 ; \delta_{2}^{+} \geq 0 ; \delta_{3}^{-} \geq 0 \text {. }
\end{aligned}
$$

Hasil perhitungan model Nadir Compromise Programming adalah $\delta_{1}^{+}=\delta_{1}^{-}=0, \delta_{2}^{+}=$ 0,006865 dan $\delta_{3}^{-}=9262,34$ dan proporsi dana yang diinvestasikan pada saham-saham yang terpilih disajikan pada Tabel 1 kolom 7.

Berdasarkan hasil yang diperoleh, maka portofolio optimal terbentuk dari 11 saham, yaitu:

Sektor Energi dan Metal

- Aneka Tambang (ANTM), proporsi dana sebesar 0.1

- Perusahaan Gas Negara (PGAS), proporsi dana sebesar 0.1

Sektor Finansial

- Bank Negara Indonesia (BBNI), proporsi dana sebesar 0.1 
- Bank Central Asia Tbk (BBCA), proporsi dana sebesar 0.1

Sektor Jasa

- Telekomunikasi Indonesia (TLKM), proporsi dana sebesar 0.1

- Hexindo Adiperkasa (HEXA), proporsi dana sebesar 0.1

Sektor Manufaktur

- Indofood Sukses Makmur Tbk (INDF), proporsi dana sebesar 0.043214

- Kalbe Farma Tbk (KLBF), proporsi dana sebesar 0.1

- Unilever Indonesia Tbk (UNVR), proporsi dana sebesar 0.056786

Sektor Perkebunan

- PP London Sumatra Indonesia Tbk (LSIP), proporsi dana sebesar 0.1

- Astra Agro Lestari Tbk (AALI), proporsi dana sebesar 0.1

Nilai expected return portofolio optimal adalah 0.033162 dan modal yang diinvestasikan adalah 7820.66 .

\section{Simpulan}

Pada paper ini telah dimodelkan permasalahan optimasi pemilihan portofolio dalam bentuk optimasi multi-tujuan. Berdasarkan hasil optimasi dari 20 saham yang dijadikan objek penelitian diperoleh 11 saham terpilih untuk membentuk suatu portofolio yang optimal. Saham-saham tersebut adalah ANTM, PGAS, BBNI, BBCA, TLKM, HEXA, INDF, KLBF, UNVR, LSIP dan AALI. Penyelesaikan permasalahan optimasi multi-tujuan ditentukan dengan menggunakan metode Nadir Compromise Programing dan menghasilkan nilai resiko portofolio 1, expected return 0.033162 dan besar modal investasi 7820.66 .

\section{Ucapan Terima Kasih}

Terimakasih kepada Departemen Matematika, Institut Teknologi Sepuluh Nopember atas dukungan dan kesempatan yang diberikan dalam melakukan penelitian ini.

\section{Daftar Pustaka}

[1] M. Amiri, M. Ekhtiari, and M. Yazdani, "Nadir compromise programming: A model for optimization of multi-objective portfolio problem," Expert Syst. Appl., 2011.

[2] K. Frajtova-Michalikova, E. Spuchl'akova, and M. Misankova, "ScienceDirect Portfolio Optimization," Procedia Econ. Financ., 2015.

[3] T. A. Saputro and M. F. Qudratullah, “Optimasi Multi Objektif Pada Pemilihan Portofolio 
Saham Syariah Menggunakan Compromise Programming (CP) dan Nadir Compromise Programming (NCP)," J. Fourier, 2017.

[4] H. Markowitz, "Portofolio Selection," J. Finance, 1952.

[5] V. Ranković, M. Drenovak, B. Urosevic, and R. Jelic, "Mean-univariate GARCH VaR portfolio optimization: Actual portfolio approach," Comput. Oper. Res., 2016.

[6] I. Iscoe, A. Kreinin, H. Mausser, and O. Romanko, "Portfolio credit-risk optimization," J. Bank. Financ., 2012.

[7] M. J. Best, Portfolio Optimization. 2010.

[8] R. Zagst, J. Kehrbaum, and B. Schmid, "Portfolio optimization under credit risk," Computational Statistics. 2003.

[9] M. Ehrgott and D. Tenfelde-Podehl, "Computing Nadir Values in Three Objectives," 2001. 